\title{
Retrofit solutions for an historic building integrated with geothermal heat pumps
}

\author{
Laura Carnieletto ${ }^{1, *}$, Giuseppe Emmi ${ }^{1}$, Marco Artuzzi ${ }^{1}$, Maria Celeste Piazza ${ }^{1}$, Angelo Zarrella ${ }^{1}$, Michele De Carli ${ }^{1}$ \\ ${ }^{1}$ Department of Industrial Engineering - Applied Physics Section, University of Padova, Via Venezia 1 - 35131, Padova, Italy
}

\begin{abstract}
Since the beginning of this century, according to EPBD Directive, Italian legislation has been focusing on existing buildings' retrofit, as they represent a large part of the national building stock. In this context, the most difficult challenge is preserving heritage and obtaining energy saving at the same time, which is the aim of the European Standard EN 16883 published in 2017. Currently there are few energy efficiency actions that can be applied to improve the energy performance of these buildings, due to the strict regulation on 'protected status'.

The case study presented in this paper gives an overview of refurbishment solutions that can get around Italian legislation for one of the oldest heritage buildings in Padova. The building complex that can be seen nowadays is the result of the grouping of several surrounding buildings, renaissance palaces and medieval towers. Energy simulations have been implemented using EnergyPlus software. The thermal behaviour of the building has been investigated considering the peculiarities of the envelope and real weather data. Internal loads and generation system schedules have been estimated based on the information obtained from the system monitoring the energy consumption. Envelope and system retrofit have been considered.
\end{abstract}

\section{Introduction}

The building sector is responsible for approximately $40 \%$ of the final energy consumption and $36 \%$ of $\mathrm{CO}_{2}$ emissions in Europe. About $35 \%$ of the building stock is older than 50 years, $75 \%$ is energy inefficient and only $0.4-1.2 \%$ of the building stock is renovated every year [1]. According to the European regulation, the biggest energy saving potential resides in the building sector and energy retrofit actions represent the improvement needed towards the reduction of energy consumption (5-6\%) and of $\mathrm{CO}_{2}$ emissions (about 5\%). From the last statistics, the European building stock has more than 160 million buildings and historical ones are the most important share of this total. Therefore, improving energy efficiency in existing buildings represents the biggest challenge and serious problems arise dealing with historical buildings. Historical buildings belong to the existing buildings category, but they need to be treated in a peculiar way. In fact, they are characterized by particular physical characteristics and they are subject to conservation principles [2]. They usually are protected as Cultural Heritage and any retrofit action is difficult to implement because often the same measures used in new buildings are not suitable for historical ones, which must be protected from the architectural and structural point of view.

Energy retrofit used in new structures can cause damages to historical buildings and for this reason, according to regulation, it is not mandatory to achieve any minimum energy requirement in buildings that are found in specific lists $[2,3]$ (derogation regime [4]). Recently, several regulations have defined stricter exemptions $[4,5,6]$ and this is the result of a new attitude among policy-makers and preservationists: energy retrofits are not seen as the cause of possible harm to cultural goods, but on the contrary, they represent an important protection tool [2]. Recent studies demonstrate the possibility to rise the supply of high temperature at the condenser side showing the suitability of the application to in historical buildings, usually characterized by low thermal insulation and high thermal capacitance [7]. Moreover, heat pump technology has become an interesting technology for new and retrofit buildings because of the new regulations which recognize the percentage of renewable energy sources represented by the heat exchanged with the heat source, giving the possibility to obtain economic incentives.

\section{Case study}

This work is part of a project on energy sustainability supported by the University of Padua. In particular, this study looks at the energy analysis of one of the oldest University buildings located in the central area of the city, developing specific retrofit solutions according to national regulations and constraints for the protection of historical-cultural architecture heritage.

This building hosts classrooms for students, libraries, meeting rooms and offices. Although it is difficult to change the building envelope, it is possible to act on the

\footnotetext{
${ }^{*}$ Corresponding author:laura.carnieletto@phd.unipd.it
} 
plant-system and its management. The improvement of the energy efficiency will be set through monitoring and optimization of energy consumption, plant redevelopment and installation of control systems in order to provide economic savings and lower environmental impact.

After introducing the evolution and changes that the building has undergone over the time, the study will present a 3D model of the building that will be analysed using dynamic simulations (Fig.1). In particular, the thermal behaviour of the building will be studied through hourly computer simulations. Further hypothesis to reduce the energy consumption and improve the energy efficiency has been made considering a Ground Source Heat Pumps (GSHP) coupled with the ground by means of vertical ground heat exchangers, which are designed via the well-known ASHRAE method [8] [9].

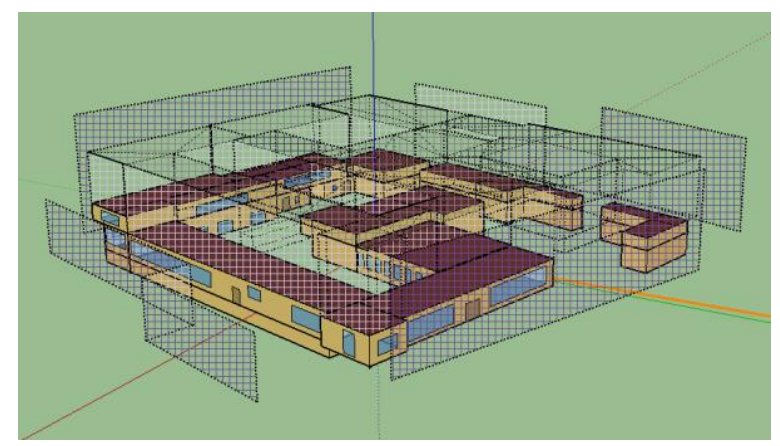

Fig. 1. Sketch-Up 3D model of the building, considering the shading of the surrounding buildings

\subsection{Building layout}

In order to define the building characteristics to implement an energy model, plants and wall stratigraphy are required. Archives which collected this information highlighted that the construction of the building is not homogeneous and dates to different eras. In the early sixteenth century, certain buildings were added to the structure in order to adapt it to the expansion of academic activity. Although the geometry of this period is well defined, a series of different buildings have been connected, settling the final configuration in the fascist period when it has been further expanded to take on today's appearance.

For this reason, it was necessary to use a criterion of continuity of materials by dividing the historical part of the fourteenth century from the most modern parts. Simplifying the energy model, same stratigraphy has been chosen for parts of the building belonging to similar historical periods. Table 1 presents an example of stratigraphy applied to the oldest walls.
Table 1. Example of wall stratigraphy.

\begin{tabular}{|c|c|c|c|}
\hline Layer & Material & $\begin{array}{c}\text { Thickness } \\
{[\mathrm{m}]}\end{array}$ & $\begin{array}{c}\text { Transmittance } \\
{\left[\mathrm{W} /\left(\mathrm{m}^{2} \mathrm{~K}\right)\right]}\end{array}$ \\
\hline \multirow{3}{*}{$\begin{array}{l}\text { Solid } \\
\text { brick }\end{array}$} & $\begin{array}{l}\text { Plaster and } \\
\text { lime }\end{array}$ & 0.015 & \multirow{3}{*}{1.13} \\
\hline & Solid brick & 0.6 & \\
\hline & $\begin{array}{l}\text { Plaster and } \\
\text { lime }\end{array}$ & 0.015 & \\
\hline \multirow{2}{*}{$\begin{array}{l}\text { Stone } \\
\text { masonry }\end{array}$} & Stone blocks & 0.6 & \multirow{2}{*}{2.09} \\
\hline & Small bricks & 0.08 & \\
\hline \multirow[b]{2}{*}{ Slab } & $\begin{array}{l}\text { Reinforced } \\
\text { Concrete }\end{array}$ & 0.8 & \multirow[b]{2}{*}{0.46} \\
\hline & $\begin{array}{l}\text { Wooden } \\
\text { plank and } \\
\text { beams }\end{array}$ & 0.15 & \\
\hline
\end{tabular}

\subsection{Heating and cooling plant}

The building is served by two gas boilers with a nominal thermal capacity of $530 \mathrm{~kW}$ each, with a useful energy efficiency equal to 0.89 . Burners of the gas boilers can modulate until to the minimum thermal capacity of $160 \mathrm{~kW}$.

The cooling demand is supplied by six air cooled chillers and also small split systems located in several zones of the building.

\section{Energy model}

Each floor of the building has been divided into thermal zones (Fig. 2) chosen appropriately according to the intended use and type of construction. For example, by applying these criteria, the ground floor classrooms belonging to the east wing of the building have been grouped into a single area, to make more effective the management of internal loads in the energy analysis.

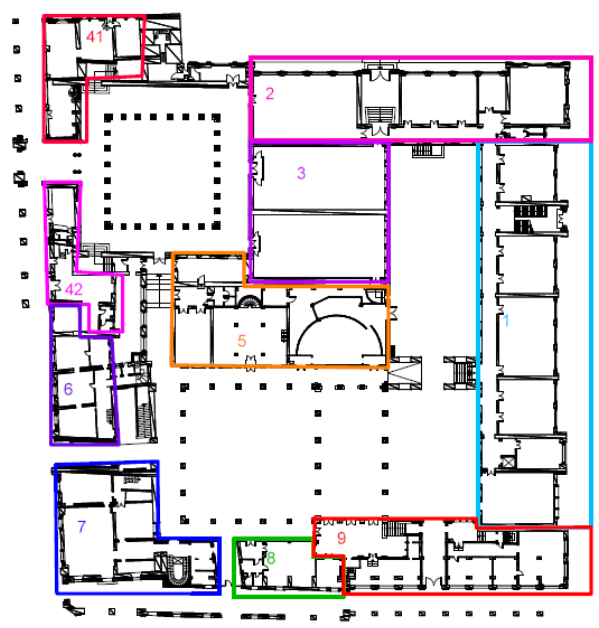

Fig. 2. Example of thermal zone division

In the model the heat gains considered depend on the presence of people and electrical devices. The thermal contribution due to the presence of people has been differentiated according to their level of activity within the building, in particular the subdivision concerns office staff, students and guests for events (for example 
conferences or guided tours). Heat gains have been estimated following the guidelines proposed in the ASHRAE manual [10] by assigning the level of activity of people. The logic with which the thermal load of the people has been implemented within the simulation tool is based on hourly tables that indicate the percentage of occupancy for each environment. Employment data were retrieved from the Fire Prevention Project; for each area, a maximum overcrowding of $70 \%$ of the maximum capacity has been assumed, calculated as the sum of the maximum capacity for each individual environment. The division between classrooms, events and offices was also maintained in the schedules by setting time profiles that followed the logic of occupation of the zones; staff and students' presence is similar.

Regarding events, however, the approximation is based on the real calendar in early 2018. Classrooms reserved primarily for conferences or sightseeing are used four times during the month for meetings lasting two to three hours. To simulate this condition, an employment profile was created for each Monday afternoon of the month. The other thermal loads considered in the model are the contributions of lighting and electrical equipment (computers, printers, etc.).

In each area the specific loads proposed have been derived from literature [11]:

- $10 \mathrm{~W} / \mathrm{m}^{2}$ for lighting loads

- $150 \mathrm{~W}$ for each computer

To calculate the heating and cooling energy demand, EnergyPlus plans to set the respective set-point temperatures and the temperature zones in which the air conditioning is envisaged. Except for the areas of the basement, where there are no heating systems, all the others have been considered as heated spaces. The temperature set-point for the heating mode has been set to $22^{\circ} \mathrm{C}$ with $60 \%$ relative humidity, while the UNI / TS 11300-1 standard [12] sets the internal temperature equal to $20^{\circ} \mathrm{C}$. This application choice derives from a daily check on the operative temperature, calculated as the average between internal air temperature and mean radiant temperature. In fact, it is clear from the graph in Fig. 3 that, by setting the room set-point temperature to $22^{\circ} \mathrm{C}$, the operative temperature respects the comfort conditions.

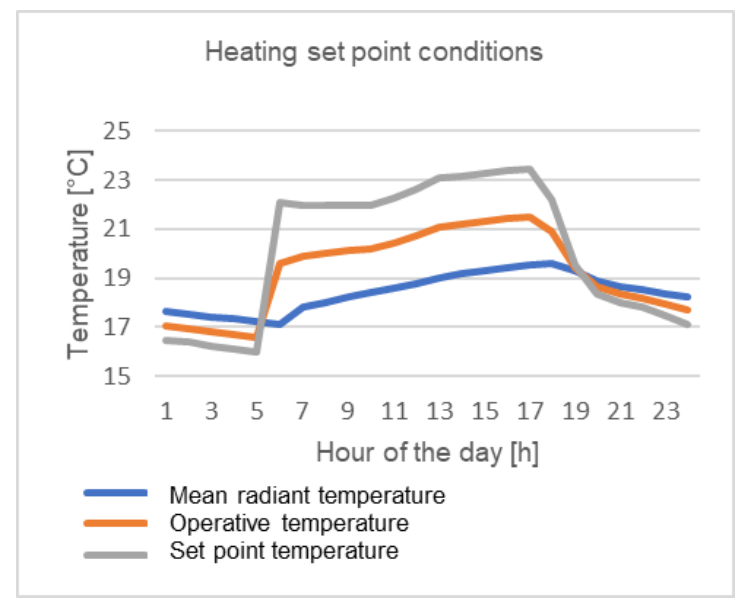

Fig. 3. Set-point conditions for a typical day in the heating season.
To precisely define the switching of the heating system an inspection on site was made and three load profiles were tracked based on real data according to the period of the year. The heating period depends on the constraints imposed by Italian legislation [13] based on the degree days of the location. Real weather data registered during the year 2017, obtained by ARPAV (Agenzia Regionale per la Prevenzione e la Protezione Ambientale Veneto) [14] has been used.

Analysing the acquired data, it was possible to note that the heating system is also activated during the weekend so that the inside temperature does not decrease too much. In fact, an excessively low temperature would lead to a higher energy consumption when the boilers are switched on as the energy to be used to bring the temperature back to the set point would be higher and there would be the risk of having to switch on to consider the ascent time.

The first step to calculate the ideal thermal load of a building involves as input the design temperature for the heating and cooling seasons, without defining input variables related to the operation of the plants. During the switching times defined in the schedules, the internal temperature of the zones is brought to a constant value, but after a prolonged inactivity of the system, the energy required to heat the environment increases considerably. For example, after the Christmas break (period between December 23rd and January 9th) a peak of energy required by the system occurs to raise the room temperature between 05:00 and 06:00 am on January 9th. In reality, the peak is not as pronounced as the installed power is not infinite. Therefore, this situation is considered as an initial error committed by the simulation to get into service.

As far as cooling is concerned, all the zones except the basement and two store areas were considered. The set point is set at $25^{\circ} \mathrm{C}$ and $60 \%$ relative humidity and air conditioning is active from 1 June to 15 September. The period has been chosen on the basis of the external temperatures that are already recorded in May in recent years.

Finally, through the EnergyPlus editor, the infiltration flow rates for each zone have been added, equal to 0.5 $\mathrm{ACH}$.

\subsection{Energy demand}

The heating energy recorded for the year 2017 is equal to about $1470 \mathrm{MWh}$. Applying the emission, distribution and control efficiencies (UNI11300-2) [15] to the simulation results, required energy demand is $1392 \mathrm{MWh}$. Comparing the obtained values, a difference of $78 \mathrm{MWh}$ is acceptable because it corresponds to about $5 \%$ of the total amount. The hourly energy calculated with the simulation gives an indication of the power required by the plant to guarantee its production. By analysing the total results of hourly energy on the three floors, excluding the first 290 hours in which the simulation settles, it has been possible to identify a peak of maximum power of $1256 \mathrm{~kW}$. By comparing this value with the power actually installed, a ratio of 1.18 is obtained which shows how the existing plant is correctly dimensioned. 
The calculated cooling requirements are $237 \mathrm{MWh}$ for real data in 2017 year. Taking the 2017 results as a benchmark, in order to compare the needs calculated with real consumption, the average monthly electricity consumption has been analysed. The consumption evidently increases during the month of June and July, while August, containing the weeks of closure of the university for the summer holidays, is consistent with the other months. Since there isn't the possibility to divide the electric consumption by type of user, to derive the consumption due to conditioning in the first analysis consumption in May, the month in which the electrical devices are generally active (lights, computers) but not the air conditioning system, they were subtracted from the values registered during the months of June and July.

Finally, for a direct comparison with the consumption calculated for the months of June and July it was necessary to transform the conditioning requirements in terms of electricity, consequently an average energy efficiency (EER) value of the refrigeration units of 2.7 was assumed, due to the presence of large machines with high efficiency but also many small autonomous split systems that serve individual zones.

The simulation results agree with the consumption, making a difference smaller than $1 \%$.

\section{Retrofit solutions}

In order to achieve an energy saving on the consumption it was decided to conduct the building simulations assuming various intervention scenarios. For example, the poor thermal insulation offered by the windows installed in the building is responsible for high incoming heat gains during the summer and high heat losses during the winter. Strategies concerning energy savings and refurbishment activities should be evaluated according to the procedure described in the European Standard [16], considering that each historic building represents a particular case study and each modification has to be designed according to the conservation principle described in standards and guidelines.

\subsection{Variation of the set-point temperature}

In Section 3 the control strategy to maintain the set point at $22^{\circ} \mathrm{C}$ has been explained. To reduce the energy consumption related to the heating of the building, it is conceivable a lowering of the set point temperature, always satisfying comfort conditions of people in the environment. BS EN 15251 [17] standard reports for various types of buildings the level of thermal comfort divided into four categories, depending on the level of perceived comfort of the people. The verification method is based on the expected average grade, i.e. the feeling that people experience in neutral temperature environment. In fact, there is a curve that calculates the percentage of unsatisfied people as a function of the thermal sensation. Since there were no possibilities to make surveys on thermo-hygrometric comfort to users, it was necessary to compare the operative temperature in the areas with the minimum required by the law to check if the minimum comfort conditions are respected. The first regulation hypothesis foresees to fix the temperature set point at $21^{\circ} \mathrm{C}$ for the whole heating season. Fig. 4 shows the operative temperature profile inside the zone 1 at the ground floor during the first three months of the year. Both in Fig. 4 and Fig. 5, the operative temperature of the initial period (about 360 hours) is around $5^{\circ} \mathrm{C}$ since the university is closed due to Christmas holidays, therefore the heating system is shut down. Neglecting the first days of results in which the simulation settles, it is evident that the operative temperature for many days is below the minimum temperature for category 3 , set at $19^{\circ} \mathrm{C}$ (Fig. 4). The hypothesis of the lowering of the temperature setpoint throughout the season is therefore not feasible.

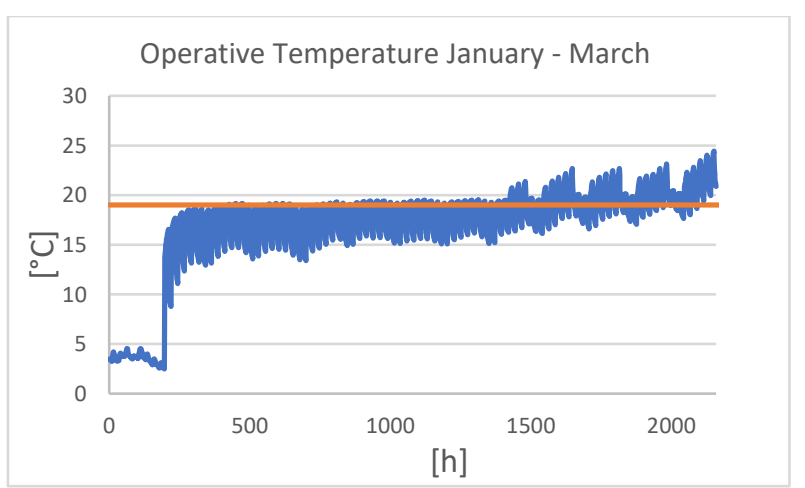

Fig. 4. Operative temperature from January to March - set point at $19^{\circ} \mathrm{C}$

To compare this hypothesis with the $22^{\circ} \mathrm{C}$ operation set in the simulation, the trend of the operative temperature for the same zone is shown in Fig. 5. It is evident that in this case the comfort sensation is respected.

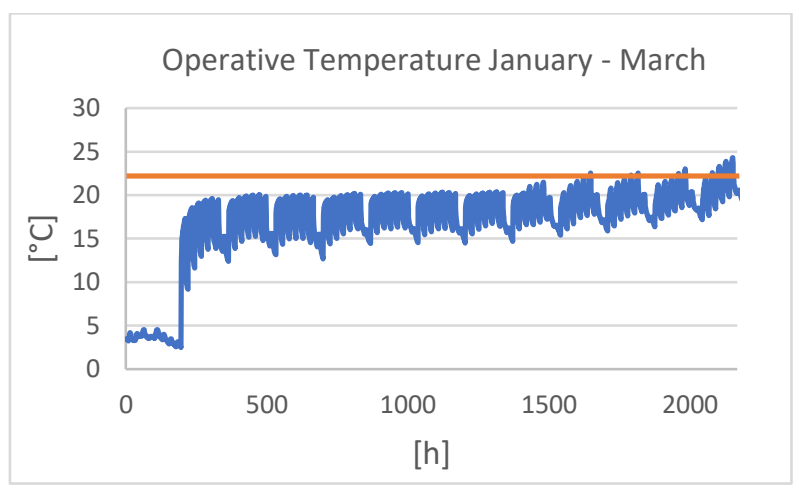

Fig. 5. Operative temperature from January to March - set point at $22^{\circ} \mathrm{C}$

\subsection{Variation of the schedule}

The second intervention hypothesis for the reduction of heating consumption is based on the change of the boiler ignition schedule and on the management of the thermostat during the weekend. As a first attempt, the setpoint temperature for Sundays has been set to $16^{\circ} \mathrm{C}$, to prevent the environments from cooling too much and the re-ignition of the systems on Monday to be energy 
intensive. The simulation returns an energy demand for heating of $1277 \mathrm{MWh}$, with a saving of about $115 \mathrm{MWh}$ compared to the original simulation. As a further step, the boiler ignition on Sunday has been removed and begin to heat an hour before Monday morning. A requirement of $1267 \mathrm{MWh}$ is obtained, slightly lower than the solution presented in the previous section. This choice may not guarantee the desired temperature in some zones. Finally, an active management of the thermostat is assumed as a function of the external temperature: when the external temperature rises above a certain value, the thermostat can be lowered because the operative temperature reaches acceptable comfort values. In this case, the schedule that regulates the set-point provides a temperature of $22^{\circ} \mathrm{C}$ during the months of January, February and December, March and November at $21^{\circ} \mathrm{C}$, April and October at $20^{\circ} \mathrm{C}$ and $16^{\circ} \mathrm{C}$ for the Sundays. The requirement thus obtained is $1207 \mathrm{MWh}$. This last solution is achievable because comfort conditions are guaranteed. It is noted that in January the total number of hours in which the temperature range is not respected is high.

For the remaining months, the percentage of hours in which the operative temperature does not satisfy the constraints is acceptable and, comparing the results obtained with the employment schedule, it should be noted that this occurs during the hours when the percentage of occupants is $25 \%$. The result obtained reconfirms the validity of this type of solution.

\subsection{Envelope}

The last intervention hypothesis foresees the replacement of old single-glazed windows with a double-glazed window. This solution is the only one that involves a real investment cost and that lends itself to a cost-benefit analysis.

The simulations have been implemented by replacing the new type of window frames where single glass is currently present (994 $\mathrm{m}^{2}$ of glazed area); from the results obtained, the annual savings on heating of about $55 \mathrm{MWh}$ is obtained, which is a low percentage of the total consumption. For this reason, this type of intervention is not economically sustainable, as the payback time of the investment would be too high.

In order to have an investment cost that is congruent to the savings that can be obtained, it is preferable to evaluate a hypothesis that includes both the management of the system and the replacement of the windows and doors. For this purpose, a simulation was carried out using the schedule with the active management of the thermostat and all the windows of the North-Eastern part of the building were replaced (about $612 \mathrm{~m}^{2}$ ). The heating demand is reduced to $1050 \mathrm{MWh}$, saving $348 \mathrm{MWh}$ compared to the original simulation.

\subsection{Ground Source Heat Pump}

The current terminal units are high temperature radiators supplied at $80^{\circ} \mathrm{C}$. Supposing to apply renewable energy sources for energy generation, radiators should be replaced with fan-coils. The supply temperature can be reduced to $45-50^{\circ} \mathrm{C}$, which can perfectly match with temperature supplied by heat pumps present in the market. At the same time, a ground source heat pump (GSHP) can be used for cooling, avoiding the use of autonomous airconditioners actually installed. Therefore, it is reasonable to consider the use of a GSHP as generation system. Considering the areas that could potentially be used for the bore field, 29 vertical ground heat exchangers $(120 \mathrm{~m}$ deep) could be installed, with a total length of $3480 \mathrm{~m}$. In order to calculate the total borehole length, the wellknown ASHRAE method [9, 8] has been used. According to this approach, the borehole length for heating or cooling is calculated by means of Equation (1).

$L=\frac{Q_{a} R_{g a}+(Q-W)\left(R_{b}+P L F_{m} R_{g m}+R_{g d} F_{s c}\right)}{\left(T_{g}-T_{m}-T_{p}\right)}$

Where:

$\mathrm{Q}_{\mathrm{a}}=$ the average annual heat load exchanged with the ground [W]

$\mathrm{Q}=$ design thermal load for cooling /heating [W]

$\mathrm{W}=$ compressor electrical power, [W]

$\mathrm{PLF}_{\mathrm{m}}=$ partial load factor of the design month

$\mathrm{F}_{\mathrm{sc}}=$ penalty factor for internal heat exchanges

$\mathrm{R}_{\mathrm{b}}=$ borehole thermal resistance $[\mathrm{m} \mathrm{K} / \mathrm{W}]$

$\mathrm{R}_{\mathrm{ga}}=$ thermal resistance of the ground for annual pulse

$[\mathrm{m} \mathrm{K} / \mathrm{W}]$

$\mathrm{R}_{\mathrm{gm}}=$ thermal resistance of the ground for monthly pulse [m K/W]

$\mathrm{R}_{\mathrm{gd}}=$ thermal resistance of the ground for daily pulse

$[\mathrm{m} \mathrm{K} / \mathrm{W}]$

$\mathrm{T}_{\mathrm{g}}=$ undisturbed ground temperature $\left[{ }^{\circ} \mathrm{C}\right]$

$\mathrm{T}_{\mathrm{m}}=$ average fluid temperature inside borehole $\left[{ }^{\circ} \mathrm{C}\right]$

$\mathrm{T}_{\mathrm{p}}=$ penalty temperature due to the interference between the boreholes $\left[{ }^{\circ} \mathrm{C}\right]$

$\mathrm{L}$ is the total borehole length $\left(\mathrm{L}=\mathrm{n}_{\mathrm{b}} \times \mathrm{H}\right.$ with $\mathrm{n}_{\mathrm{b}}$ as the number of boreholes and $\mathrm{H}$ the depth of each borehole). The value of L is usually evaluated for both heating and cooling conditions yielding different bore field lengths. If the GSHP covers the entire building energy load, the larger of the two lengths calculated is the required borehole length. However, in some cases, a smaller length is selected to reduce the investment cost; in this case, a hybrid system in installed. Heat pumps can operate at temperature close to $-5^{\circ} \mathrm{C}$ in heating and up to $40^{\circ} \mathrm{C}$ in cooling [18], considering the heat-carrier fluid and the properties of the ground.

Figure 6 shows the monthly energy profile used to determine the borehole length, considering a peak power of $200 \mathrm{~kW}$ both for heating and cooling; this is part of the total building load profile. 


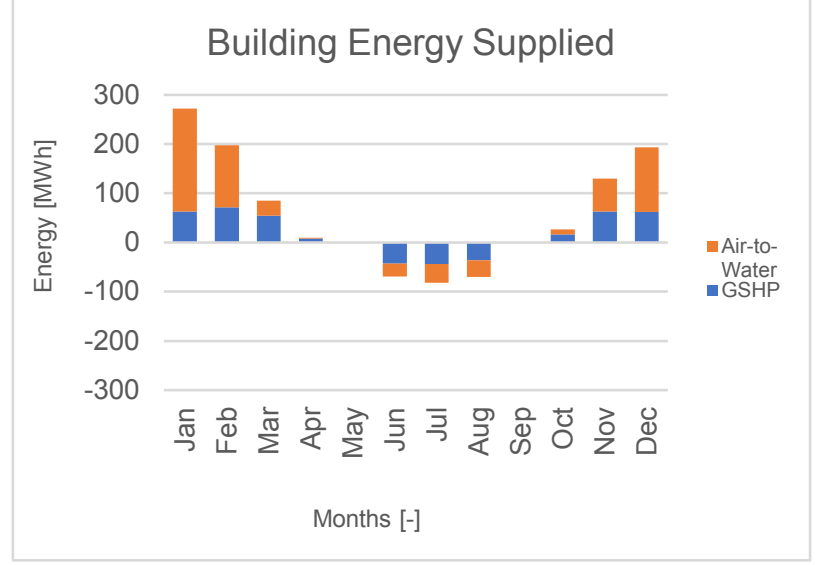

Fig. 6. Building Energy Supplied for heating and cooling by the two generation systems

Table 2. Properties of the ground in Padova.

\begin{tabular}{|l|c|}
\hline Thermal conductivity $[\mathrm{W} /(\mathrm{m} \mathrm{K})]$ & 2 \\
\hline Density $\left[\mathrm{kg} / \mathrm{m}^{3}\right]$ & 1275 \\
\hline Specific heat $[\mathrm{J} /(\mathrm{kg} \mathrm{K})]$ & 1760 \\
\hline Undisturbed temperature $\left[{ }^{\circ} \mathrm{C}\right]$ & 13.4 \\
\hline
\end{tabular}

Table 3. Characteristics of the borehole heat exchanger.

\begin{tabular}{|l|c|}
\hline Type & 2 U-tube \\
\hline Pipe & 26 \\
\hline Inside diameter [mm] & 32 \\
\hline Outside diameter [mm] & 0.35 \\
\hline $\begin{array}{l}\text { Thermal Conductivity of material } \\
{[\mathrm{W} /(\mathrm{m} \mathrm{K})]}\end{array}$ & 120 \\
\hline \hline Borehole diameter [mm] & 1.5 \\
\hline $\begin{array}{l}\text { Thermal conductivity of the grouting } \\
\text { material [W/(m K)] }\end{array}$ & 120 \\
\hline Borehole depth [m] & 7 \\
\hline Borehole spacing [m] & \\
\hline \multicolumn{2}{|l|}{} \\
\hline
\end{tabular}

Table 4. Energy efficiency of the heat pump

\begin{tabular}{|c|c|c|}
\hline \multicolumn{3}{|c|}{ Design values } \\
\hline & Heating & Cooling \\
\hline COP / EER [-] & 3.5 & 4 \\
\hline \multicolumn{3}{|c|}{ Mean seasonal values } \\
\hline & Heating & Cooling \\
\hline COP /EER [-] & 4 & 4.5 \\
\hline
\end{tabular}

Implementing the characteristics showed in Tables 2, 3 and 4, and setting the heat pump entering fluid temperature at $5^{\circ} \mathrm{C}$ for heating $(\Delta \mathrm{T}=3 \mathrm{~K})$ and $30^{\circ} \mathrm{C}$ for cooling $(\Delta \mathrm{T}=3 \mathrm{~K})$, the borehole length obtained for heating is $5400 \mathrm{~m}$, and $3700 \mathrm{~m}$ for cooling, with a penalty temperature of about $0.8^{\circ} \mathrm{C}$.

The result is acceptable considering the available total length of $3480 \mathrm{~m}$, which satisfies roughly $32 \%$ of the cooling energy demand and $28 \%$ of the heating energy demand obtained after the retrofit solutions explained in
Section 4. The remaining energy requirement can be provided by air-to-water heat pumps.

Supposing to have more areas available to install GSHP, a second hypothesis has been studied sizing the bore field to supply all the cooling energy demand. The peak power for cooling in this case is $400 \mathrm{~kW}$, obtaining a $7100 \mathrm{~m}$ borehole length for cooling, which corresponds to 58 boreholes. Even if the cooling demand is $75 \%$ satisfied, only the $42 \%$ of the heating power is supplied, requiring as a back-up an auxiliary system.

Further analysis will be done to study the coupling of the two different devices, optimizing their working schedule based on the season.

\section{Conclusions}

The project described arises from the awareness of how the refurbishment of the existing building heritage is one of the most relevant issues that are encountered in the field of sustainability. Energy simulation is an increasingly used method to analyse and plan retrofit and energy efficiency projects. In fact, results obtained showed that, using real climate data, the simulation returns values consistent with real consumption.

The annual heating requirement calculated, in fact, is equal to $1392 \mathrm{MWh}$, comparable with the $1470 \mathrm{MWh}$ that correspond to the consumption of thermal energy in 2017. For the cooling season, however, the requirement of 237 MWh / year has been obtained, in accordance with real consumption in June and July.

The developed model can be used to improve the management of the plants and / or to design energy efficiency measures, even though, for a building subject to historical protection, it is very complex to work on the envelope. Among the hypotheses of intervention analysed, those related to the management of the plant proved to be the most effective. A saving of about 185 MWh is achievable with a more efficient management of the thermostat while a more significant action as the replacement of windows and doors is too expensive to save a small amount of energy.

Considering the quality of the data currently available on the plant engineering features of the enclosure, the optimal solution results to be the partial replacement of the windows favouring the North and East orientation of the building, generally more critical from the point of view of heat losses, combined with a dynamic management of the thermostat according to the month of the heating season.

From the system point of view, high temperature terminal units with supply temperatures around $80^{\circ} \mathrm{C}$ (radiators) can be replaced with fan-coils. The supply temperature can be therefore reduced to $45-50^{\circ} \mathrm{C}$. The heat pumps present in the market can meet this requirement and at the same time can be used for cooling. It is therefore reasonable to consider the use of geothermal heat pumps as generation system, sizing 29 borehole heat exchangers to satisfy the $32 \%$ of the cooling demand and $28 \%$ of the heating demand.

The main results of the study show how renewable energy sources can be exploited in retrofit solution of historical 
buildings. The simulations results highlight the energy saving improvements that can be obtained optimizing the operating schedule according to internal loads and external climatic conditions, and the substitution of terminal units allow the coupling with ground source heat pumps and/or air-to-water heat pumps.

\section{Acknowledgments}

The authors wish to thank the University of Padua for having granted the analysis of the building.

\section{References}

[1] European Commission. [Online]. Available: https://ec.europa.eu/energy/en/topics/energyefficiency/buildings. (last visit: 27/12/2018)

[2] A. L. Webb, Energy retrofits in historic and traditional buildings: A review of problems and methods, Energy 137, pp. $991-1000,2017$.

[3] A. Galatioto, G. Ciulla, R. Ricciu, An overview of energy retrofit actions feasibility on Italian historical buildings, Energy 137, vol. Issue C, pp. 991-1000, 2017.

[4] L. Mazzanella, Energy retrofit of historic and existing buildings. The legislative and regulatory point of view, Energy and Buildings 95, pp. 23-31, 2015.

[5] R. Cochrane, Preservation at the Energy Code Table: What the IECC Changes Mean for Historic Buildings Owners, in https://forum.savingplaces.org/connect/blogs/forumonline/2014/07/09/preservation-at-the-energy-code-table, Preservation Leadership forum Blog. 2014.

[6] Z. Bastian, M. Spiekman, Section 4.3 - Energy efficiency levels and certification, in Energy efficiency solutions for historic buildings, A handbook, Berlin, Basel, Birkhäuser,

A. Troi, Z. Bastian, 2014, pp. 92-8.

[7] G. Emmi, A. Zarrella, M. De Carli, S. Moretto, A. Galgaro, M.. Cultrera, M. Di Tuccio, A. Bernardi, Ground source heat pump systems in historical buildings: two Italian case studies, Energy Procedia, 133, pp. 183-194, 2017.

[8] S.P. Kavanaugh, K. Rafferty, Ground Source Heat Pumps. Design of Geothermal Systems for Commercial and Institutional Buildings, ASHRAE, Atlanta, US, 1997.

[9] ASHRAE, HVAC Applications, ASHRAE handbook, ASHRAE, Atlanta, US, 2007, Ch.32.

[10] ASHRAE, ASHRAE Handbooks: Fundamentals - SI Edition, ASHRAE, Atlanta, US, 2005.

[11] N. Rossi, in Manuale del Termotecnico, Hoepli, 2014, p.1301, Tab. 32.15 (in Italian)
[12] UNI. UNI-TS 11300 - Parte 1: Determinazione del fabbisogno di energia termica dell'edificio per la climatizzazione estiva ed invernale, Milan, Italy, 2014

[13] Decree $n .4$ of the President of the Republic of Italy, 26 August 1993

[14] Agenzia Regionale per la Prevenzione e Protezione Ambientale del Veneto, Available online:

http://www.arpa.veneto.it/previsioni/en/html/meteo_veneto.php (last visit: June, 2018)

[15] UNI-TS 11300-2, Prestazioni energetiche degli edifici - Parte 2: Determinazione del fabbisogno di energia primaria e dei rendimenti per la climatizzazione invernale, per la produzione di acqua calda sanitaria, per la ventilazione e per l'illuminazione in edifici non resi, Milan, Italy, 2014.

[16] CEN. UNI EN 16883:2017, Conservation of cultural heritage Guidelines for improving the energy performance of historic buildings, 17 May 2017.

[17] UNI EN 15251:2007, Indoor environmental input parameters for design and assessment of energy performance of building addressing indoor air quality, thermal environment. lighting and acoustic, 2007.

[18] P. Monzó, M. Bernier, J Acuña, P. Mogensen, A Monthly Based Bore Field Sizing Methodology with Applications to Optimum Borehole Spacing, in ASHRAE Transactions, Volume 122, Part 1, 2016. 